\title{
Big Data Big Impact: How Firms are Using Social Media for Innovation and Better Performance
}

\author{
Ali El Samra ${ }^{a}$, Leonidas Anastasakis $^{b}$, Pavel Albores $^{c}$, Victoria Uren ${ }^{d}$ \\ $a^{*}$ Aston Business School, Aston University, Birmingham, United Kingdom, elsamraa@aston.ac.uk \\ ${ }^{b}$ Aston Business School, Aston University, Birmingham, United Kingdom, I.anastasakis@aston.ac.uk \\ ${ }^{c}$ Aston Business School, Aston University, Birmingham, United Kingdom, p.albores@aston.ac.uk \\ ${ }^{d}$ Aston Business School, Aston University, Birmingham, United Kingdom, v.uren@aston.ac.uk
}

Received: 28 August 2018, accepted: 11 Septembre 2018, published: 31 January 2019

\begin{abstract}
Firms continuously attempt to find new sources of information to innovate and achieve a superior performance. Big data present on social media platforms represents one of the new sources of information that firms are starting to rely on. This paper is an exploratory study to examine how firms are making use of social media and what kind of impact the social media use have. An online questionnaire was used to collect data from 75 firms in the United States. Our findings suggest that Big Data, in the form of social media data, has an impact on the firm's innovativeness and performance, and that IT capability potentially plays a mediator role in this relation.
\end{abstract}

Keywords: Big Data, innovation, performance, qualitative, IT capability

\section{INTRODUCTION}

The internet has provided organizations with new methods to access information. Initially, before Web 2.0, the web was designed to have the information flowing in one direction, where content was made available online for users to consume, which was at that time a revolution by itself. Then when Web 2.0 arrived, the information flow became in two directions instead of one: users can now read and write and not only read. The users' ability to create content lead to the availability of numerous amounts of data, of Big Data. This was made possible through the availability of different social media platforms. Social media is often related to Big Data as it was one of the triggers of it due to the large amount of unstructured data accumulated on social media platforms (Vesset, 2013).

Organizations are trying to benefit from Big Data in different perspectives. Social media data represents an example of Big Data. Due to its popularity among consumers, social media became one of the most popular platforms for organizations to acquire knowledge, as user-generated content - enabled by the internet - became the primary source of information for both consumers and organizations (Yu et al., 2012). Organizations are adopting social media for different purposes such as operations and innovation management (Kiron et al., 2012), marketing and advertisement (Bennett, 2013), identifying business partners and customers (Michaelidou at al., 2011; Wang et al., 2016), and creating customer relationships (Swani et al., 2014).

Previous studies have investigated the impact of social media on innovation and on performance in different contexts: Nguyen et al. (2015) studied the impact of social media on brand innovation; Lam et al. (2016) examined the impact of social media initiatives on operational efficiency and innovativeness; Tajvidi and Karami (2017) investigated the role of social media on firm performance in hotel industry; while Wu (2016) looked at the role of social media and its relation to performance in chain store industry. Although these studies tested the impact of social media on innovation and on firm's performance, there are very limited studies that went deeper to identify what are the social media initiatives 
being applied by firms, which ones have an impact, and if mediators exist among these relationships. Identifying and classifying social media initiatives is important to understand how firms are making use of social media data. It also allows to identify what is the impact of these initiatives on the firm and how can they employ social media to achieve their goals. To fill this gap, this exploratory study aims to identify social media initiatives, explore if any mediators exist between the identified social media initiatives and social media impact, and propose a conceptual model to test these relations.

This paper makes three main contributions. First, it identifies four new social media initiatives. Second, it suggests a mediating role of IT capability between social media initiatives and social media impact on innovation and performance. Finally, it proposes a conceptual model to test these relationships. The remainder of this paper is organized as follows. In section two, a literature review and theoretical framework is presented. The research methods are discussed in section three. After that, findings are stated in section four. Finally, we present our discussion and conclusions in section five.

\section{LITERATURE REVIEW AND THEORETICAL FRAMEWORK}

\subsection{Defining Big Data}

"Big Data is the storage and analysis of large and or complex data sets using a series of techniques including, but not limited to: NoSQL, MapReduce and machine learning" explain Ward \& Barker (2013). It is the data that is unmatched in scale and scope in relation to a given phenomenon as Shroeder (2012) states. Big Data is often sources of data accumulating large amounts at high speed. At the World Economic Forum in Davos in Switzerland 2012, Big Data was a topic that grabbed a lot of attention. Lohr (2012) states that "Big Data, Big Impact" report, that was revealed during the forum declared data a new class of economic asset, like currency or gold. He adds that Big Data is a marketing term, but also a phrase summarizing how trends are advancing in technology, and opening doors to new approaches changing the way we understand the world and make decisions. The data is growing at a fast pace, with more streams of data and new ones as well. "There are now countless digital sensors worldwide in industrial equipment, automobiles, electrical meters and shipping crates. They can measure and communicate location, movement, vibration, temperature, humidity, even chemical changes in the air", Lohr explains.

Parise et al (2012) define Big Data as the ability that allows organizations to draw out value from large amounts of data, while Cornwell (2013) explains that it is an attempt to handle big and complicated amounts of data which organizations can't store, process and analyse through traditional tools. It also includes unstructured data that can't be analysed easily. This unstructured data includes data coming from social networks, such as Facebook, Twitter, and Linkedln. This stream of data itself is an asset for companies if they were able to reveal the hidden value within this data once it is analysed in the right way.

The main reason behind the start of Big Data is the huge amount of data that started being produced by different sources. As the size of this data grew more and more, the need for a different approach to analyse this data became crucial. Vesset (2013) explains that companies like Google, Yahoo, Amazon, Facebook, and Twitter triggered Big Data by producing big amounts of click stream data which is useful only if gathered and analysed. He adds: "The volume and flow of information was such that traditional web analytics methods were not capable of handling it". Add to that the huge amount of data that organizations had for more than 30 years which kept growing with new volumes of multimedia data. Gary Curtis (2012), explains that the challenge was in combining all this data and making sense out of it, and that very few organizations are making use of the full potential of the data they have. Tapping into this asset was a must for organizations. "Big data is changing business and creating new risks and opportunities. Savvy organizations are looking for ways to put it to work effectively", admits Viswanathan (2012).

\subsection{Social media definitions}

Social media include varieties of online applications such as social networking sites (SNSs), microblogs, blogs, forums, video posting, photography sharing, service reviews, product reviews and different types of communities(Aichner \& Jacob, 2015). People are using different social media platforms such as Twitter, Facebook, Instagram, YouTube, TripAdvisor, Wikipedia, and other online forums to talk about their encounters and connect to other users (Chen et al., 2011).

Social media facilitates the content generation process and information sharing by individuals (Kim \& Johnson, 2016). Correa et al. (2010) establish social media as the consumption of internet or digital media that doesn't have much to do with traditional information media usage, providing a mechanism for the users to interact, communicate, and connect 
with each other through online platforms and instant messaging (Dubihlela and Rundora, 2015). Kaplan \& Haelein (2010) define social media as "a group of internet-based applications that build on ideological and technological foundations of Web 2.0 and allows the creation and exchange of user generated content ". Social media are usually referred to as applications that are either fully based on content created by users, or significantly dependent on the content created by users to increase the value of the service or the application (Kangas et al., 2007). Social media is known as a powerful marketing tool, described as a communication strategy that motivates users to transfer messages to their networks, creating massive exposure growth opportunities for products and services (Cruz and Fill, 2008).

Influenced by new technologies such as social media platforms, firms nowadays operate in the age of real-time information (Dubihlela and Rundora, 2015). For social media use in business activities, Mount and Garcia (2014) suggest a four step framework: scan, engage, learn and internalize. Social media as a communication channel assists business organizations to achieve their different objectives such as customer service, marketing, branding, advertisement and public relations (Tajvidi and Karami, 2017). Social media is considered as an effective online platform for organizations to interact and connect with big numbers of potential customers enabling them to share information about their business products or services directly (Schaupp and Elanger, 2013), since it attracts users searching for information about products or services they want to buy and thus increases the purchasing intention of customers (Hajli, 2013).

\subsection{Social media initiatives}

A firm's strategy when using social media depends on the objectives it is willing to achieve from that use. Lam et al. (2016) refer to firm's adoption of social media for different organizational purposes as social media initiatives, defining it as the firm's strategic use of social media. They classify firm's social media initiatives into six categories:"1) employee collaboration and internal communication, 2) inter-firm cooperation and supply chain management, 3) new product development and idea generation, 4) public relations and corporate social responsibility, 5) customer service and customer relationship management, and 6) sales and marketing". Lam et al. (2016) classification is based on reports rather than empirical studies. The majority of current studies tend to pick up on a specific initiative of social media usage to study it and its impact on the firm. For example, studies focus on social media usage (at firms' level) for: marketing (Yadav and Rahman, 2017; Change et al., 2018; Seo and Park, 2018), public relations (Selvamany and ChiaHern, 2016; Rodriguez, 2016; Bashir and Aldaihani, 2016), product development (Bashir et al., 2017; Carr et al., 2015; Hidayanti et al., 2018) and customer relationship (Trainor et al.,2014; Baird and Parasnis, 2011; Maecker at al., 2016 ) to name a few. To the best of our knowledge, there are no studies that attempted to identify and classify firms' social media initiatives.

\subsection{Social media impact}

The focus in this study is on social media impact at firms' level. Just like scholars studied different social media initiatives, they also addressed different impacts of social media usage. Kim et al. (2015) explored the relationship between a firm's (restaurant) social media activity and firm value, suggesting a positive effect of the firm's activities on social media on firm value. Tajvidi and Karami (2017) studied the effect of social media use in SMEs, where their findings demonstrated a positive and significant relationship between social media use and firm performance. In a different study, Wu (2016) also examined the impact of social media marketing strategy on organizational performance in the chain store industry in Taiwan. Meanwhile, Luo et al. (2013) tried to link social media and firm equity value. Their study found that social media-based metrics are significant indicators of firm equity value. Other scholars addressed social media impact on innovation: Lam et al. (2016) explored the effect of social media on organizational innovativeness and found out that social media initiatives lead to both operational efficiency and innovativeness; while Nguyen et al. (2015) examined the effect of social media initiatives on brand innovation suggesting that social media strategic capability positively affects brand innovation. However, when it comes to exploring mediators or moderators between social media initiatives and its impact/outcome, studies are limited. Examples of the mediators/moderators considered in studies involving social media initiatives and its impact (outcome) at firms' level include: social capital (Kamboj et al., 2017), brand trust and brand equity (Khadim et al., 2018), corporate reputation (Boateng and Okoe, 2015), and brand loyalty (Choi et al., 2018). As such, this study intends to empirically identify social media initiatives at firms' level, and explore new mediators. 


\subsection{Theoretical background}

Since this is an exploratory study aiming to develop a conceptual model, grounded theory is the theoretical underpinning. Grounded theory was initially proposed by Glaser and Strauss (1967), and was edited by different scholars including Strauss and Corbin (1990) and Charmaz (2006). The theory clarifies real world experiences and combines the need for and the promise of relevancy about what is happening within a particular area of research (Glaser, 2003). Seeking to build up exploratory models that are grounded in empirical data, grounded theory is an inductive qualitative research method (Creswell, 2012); a methodology to develop theory based on data (Geyer and Krumay, 2015). Grounded theory is defined as "as a qualitative research method that uses a systematic set of procedures to develop an inductively derived grounded theory about a phenomenon" (Strauss and Corbin, 1994). Through a grounded theory approach, researchers can extract themes, explain, and conceptualize a phenomenon (Falt et al., 2017). According to Charmaz (2014), grounded theory methods "consist of systematic, yet flexible guidelines for collecting and analysing qualitative data to construct theories from the data themselves. Thus researchers construct theory 'grounded' in their data".

Glaser and Strauss (1967) recommend that researchers should not have any preconceptions to guarantee that the theory was totally grounded in the data: "An effective strategy is, at first, literally to ignore the literature of theory and fact on the area under study". Thus, they suggest to perform a literature review after data analysis. On the contrary, Strubing (2007) and Urquhart (2007) both explained that for developing and interpreting a grounded theory research, it is important to have preceding empirical knowledge while keeping an open mind to allow new themes to emerge. In our study, we adopted Strubing (2007) and Urquhart (2007) approaches and performed a literature review ahead of data collection and analysis. As we are aiming to develop a conceptual model in our exploratory study, we don't have any hypotheses to test, which is what the grounded theory require/support, in order to make sure that results/themes were developed from the data itself (Strauss and Corbin, 1990).

\section{METHODS}

The research follows a qualitative approach, which was seen to perfectly fit the study aims and objectives, since it is an exploratory study attempting to identify social media initiatives and develop a conceptual model related to its impact.

\subsection{Data collection}

\subsubsection{Questionnaire}

The data was collected through an online panel. The questionnaire used for data collection included 28 questions. Out these questions, three questions were for targeting, 15 questions were to gather descriptive information, and 10 questions were opened ended questions to collect the qualitative data. We targeted companies that use social media (have official social media accounts/pages), and participants with a managerial position (manager or above) who are aware of how their company uses social media and for what purposes. Any participant who didn't satisfy this criteria, and who completed the questionnaire in less than 7 minutes, was automatically disqualified. We also added a minimum character count for the open ended questions, so that we don't end up with meaningless answers. The total number of completed usable questionnaires was 75 .

\subsubsection{Sample}

Other than the criteria mentioned above, we targeted companies in the United States market. In order to reach our 75 target, we ended up targeting a total of 284 participants: 75 were accepted, 93 didn't use social media, 35 were not in a managerial position, 44 didn't have the knowledge about their company's use of social media, 4 finished the survey in less than 7 minutes, and 33 had un-usable data in the open ended questions (for example copy-paste answers for all questions).

\subsubsection{Descriptive analysis}

Within our sample, firms operated in 22 different industries including: education (14 firms, 18.66\%), retail (11 firms, $14.66 \%)$, food and beverages (7 firms, 9.33\%), and information technology (7 firms, 9.33\%). These firms served: businesses -B2B (11 firms, 14.67\%), customers - B2C (24 firms, 32\%) and both B2B and B2C (40 firms, 53.33\%). When asked if they had a social media team, $76 \%$ said they had a dedicated social media team while $24 \%$ said they didn't have one. Within the firms who had a dedicated social media team, this team belonged to different departments: marketing 
(24 firms, 42.11\%), technology (12 firms, 21.05\%), customer service (9 firms, 15.79\%), advertisement (5 firms, $8.77 \%)$, independent department ( 5 firms, $8.77 \%$ ), and other departments ( 2 firms, 3.51\%). Other sample characteristics can be seen in table 1.

\begin{tabular}{|c|c|c|c|c|c|c|c|c|}
\hline Firm Size & $\mathbf{n}$ & $\%$ & SM Team Size* & $\mathbf{n}$ & $\%$ & $\begin{array}{l}\text { SM Annual Spending } \\
\%\end{array}$ & $\mathbf{n}$ & $\%$ \\
\hline $0-50$ & 18 & 24.00 & $0-2$ & 14 & 24.56 & $0-2$ & 29 & 38.67 \\
\hline $51-250$ & 19 & 25.33 & $3-5$ & 13 & 22.81 & $3-5$ & 22 & 29.33 \\
\hline $251-500$ & 9 & 12.00 & $6-10$ & 9 & 15.79 & $6-10$ & 15 & 20.00 \\
\hline $501-1000$ & 7 & 9.33 & $11-20$ & 9 & 15.79 & $11-20$ & 8 & 10.67 \\
\hline $1000_{+}$ & 22 & 29.33 & $20+$ & 12 & 21.05 & $20+$ & 1 & 1.33 \\
\hline
\end{tabular}

Note: Table 1 presents the characteristics of responding firms

*Social Media team size within the firms who said they have a dedicated social media team

\subsection{Data analysis}

\subsubsection{A qualitative approach}

Often when people try to differentiate between quantitative research and qualitative research they link the use of numbers to the first and the use of words to the second respectively (Creswell, 2014). A main difference between quantitative and qualitative approaches, related to the role of theory in relation to research, is that a quantitative research applies a deductive approach with a purpose of testing a theory, while a qualitative research applies an inductive approach with a purpose of generating a theory (Bryman 2012; Creswell 2014). The research questions often influences the research method used. "Certain types of social research problems call for specific approaches", explains Creswell (2014). The nature of a quantitative research is to perform statistical analysis aiming to conclude with a statistical interpretation, while the nature of a qualitative research is to perform text analysis aiming to conclude with themes and patterns interpretation (Creswell 2014; Bryman 2012). Since our study is exploratory in nature rather than testing a theory, and thus will follow an inductive approach instead of a deductive one, our research follows a qualitative approach.

\subsubsection{Thematic Analysis}

One of the most common approaches to qualitative data analysis is thematic analysis (Bryman 2012). Thematic analysis is defined as "a method for identifying, analysing and reporting patterns (themes) within data", according to Braun and Clarke (2008). They explain that a theme "captures something important about the data in relation to the research question, and represents some level of patterned response or meaning within the data set". Themes can be identified at different levels: at a semantic/explicit level, or at a latent/interpretative level (Boyatzis, 1998). Braun and Clarke (2008) state that themes are identified within the surface meanings with a semantic approach, while a latent approach examines the underlying ideas and conceptualizations behind the semantic meaning of the data.

Another popular qualitative data analysis approach is content analysis. The categories used in content analysis are not extracted from the data. Flick (2014) explains: "an essential feature is the use of categories that are often derived from theoretical models: that is, categories are brought to the empirical material and not necessarily developed from it". He adds that in the qualitative content analysis approach, building a coding frame is central.

Since we want to identify new social media initiatives and thus extract codes and themes from the data itself rather than from literature, we decided to use thematic analysis rather than content analysis. Braun and Clarke (2008) developed a process of 6 steps to do a thematic analysis, which we followed in our analysis: 1) familiarizing yourself with you data, 2) generating initial codes, 3) searching for themes, 4) reviewing themes, 5) defining and naming themes, 6) producing the report. 


\section{FINDINGS}

Analysing the data using a thematic analysis approach resulted in a total of 11 themes. These themes are presented next, with examples of what participants said in relation to each theme.

\subsection{Customer support}

Under this theme, there were two main categories: connecting with customers and communicating with customers. Participants stated that they use social media to connect with the public, in particular with younger generations. It represents a platform where they can interact directly with their customers: "it (social media) serves as a help desk of sorts for immediate answers to questions or problems", said one participant. Another participant added: "it is important for us to (be) present and responsive so that our customers feel like we are there for them". Social media creates a certain type of connection between firms and customers as one participant explains: "it (social media) also makes customers feel like they have (an) instant and responsive connection to us". Participants also stated that they use social media as a communication channel where they can share any type of messages with their customers, they explained that they use it to "reach millions"; "communicates with the masses"; "keep current and new clients up to date"; "advise followers of upcoming events"; "communicate with stakeholders".

\subsection{Product feedback and ideas}

When it comes to product related matters, firms are using social media to get feedback about current products and to get ideas for new ones. Firms consider social media an important platform to acquire direct feedback from their customers. One participant stated that his/her firm uses social media to "receive customer feedback as well as customer concerns, complaints, and comments", another added "we get consumer reviews and product feedback from our buyers". Participants also highlighted how beneficial the feedback received through social media is: "I will say that feedback via social media has enabled us to make significant improvements in the ways we go about our business", as one participant explained. Firms also use social media to acquire ideas for new products. They benefit from the social media platform to harvest ideas people are sharing. Some examples of what participants said included: "we go out and canvass people and their innovative ideas"; "getting feedback on products and services as well as new ideas"; "they communicate with us ideas"; "it's where we sometimes get new ideas".

\subsection{Marketing and advertisement}

One of the main uses for social media is for marketing and advertisement, and our findings confirm that. Firms are using social media to share information about new products, to attract new customers, and to reach their target audience. In relation to advertising new products, some examples of what participants said about this included: "keep clients up to date on new products"; "release news of new products to the market"; "reach our individual customers with new products"; "our main focus for using social media is to market new products". When it comes to using social media for marketing and advertisement, participants explained: "it helps us a lot with marketing"; "it's an effective and low cost way to advertise"; "we use it to promote what's going on with our retailers and sponsors"; " to run promotions, to advertise specials in store and online, to advertise sales". Social media is also used by firms to attract new customers, examples of what participants said included: "we use social media to obtain and track new clients"; "to gain new customers"; "to attract new customers"; "to attain new customers". Participants also stated that social media allows them to reach audience that they can't reach through other advertising options: "the newest generation operates online more than the previous generations"; "it helps get a population we can't really get from newspapers or radio"; "our target shopper is female 25 - 54 and that's who uses this platform (Facebook) of social media".

\subsection{Needs identification}

The participants explained that they use social media to identify customers' needs, which allows them to customize their offerings accordingly, in order to meet those needs: "we use social media to identify the exact need so we can customize the experience of the customer", stated one of the participants. Some examples of what participants said of why they use social media in relation to identifying customers' needs included: "to identify customer needs"; "to analyse customer needs"; "to create knowledge about our customer needs"; "to find what the consumers need". When explaining how social media helped his firm to identify their customer needs, one participant stated:" we were able to pinpoint exactly what they were looking for and how we can accommodate them moving forward". 


\subsection{Data collection and analysis}

Firms are collecting data and analysing it to turn data into information. This data can provide them with different insights and added value. One participant explained that his/her firms "collects the data through analytic programs to determine exactly what types of interaction that our consumers are engaging in and adapt our marketing techniques accordingly". Another participant explained that they "collect it within IT department both onsite servers as well as (on) cloud based servers". Participants also emphasized the importance of the analysis part as well, explaining that "client comments are collected and analysed by our team to mine for relevant information and/or suggestions". Other examples of what participants said in relation to data collection and analysis included: "we analyse the data provided by the analytics and reach out through social media to determine what the problems were in specific"; "the social media team provides data and analytics"; "we collect and analyse the data using Google AdWords and Google Analytics".

\subsection{Talent Acquisition}

The participants explained that they use social media for recruitment. They explained that they can attract talent by posting job openings on social media: "we use it for job recruiting to show our benefits and the positions we need to fill", explained one of the participants. New generations go job hunting on social media nowadays, so the participants explained that hiring through social media allows them to target and acquire talent that might not be available through other recruitment processes. "We use it (social media) to recruit better hires", one participant explained, while another added:" newer generations use social media as their platform for job searching, so without social media, we would miss out on those potential employees".

\subsection{Competitors monitoring}

One theme that emerged from the data was related to competitors. Firms find social media a simple but effective method to keep an eye on what their competitors are doing. It allows them to track their competitors' activity by checking their pages, public messages, and any offerings they have. Some examples of what participants said about tracking competitors on social media included (using social media) : "to compare products, search out competitors"; "to learn what the competition is doing on their social media pages"; "to keep an eye on competitors". Firms also track their competitors on social media to compare themselves to the competition. "We also look at the competition to see how we measure up", stated one of the participants.

\subsection{Performance}

A theme that emerged from the data was related to the performance of the firm, and how social media usage enhances it. Participants indicated how their firms' business has grown as a result of their social media presence: "if we were not on social media our growth would be nowhere near what it is and our business would be failing"; "we would have little to no business if we were not responsive and present on our social media platforms";" we have grown tremendously and a constant social media presence is one of the reasons for that growth". One participant explained the direct effect social media usage had on their sales: "Business has improved maybe 40 to $45 \%$ more since we have expanded our business on social media". Another participant stated how social media usage impacted their operations:" to be able to develop our products and expand our operations more efficiently, creating a higher ROI and increasing revenue in general".

\subsection{Innovation}

Another theme extracted from the data was about how social media usage enhances the innovativeness of the firm. Participants explained that the information gathered through social media is important to their firms' innovativeness: "depending on the information gathered, our technology team and other senior department personnel determine what new innovations should be implemented, and/or what existing processes/tools/formats need adjustments". Some even indicated that the social media team plays an important role in the innovation process:" the designated member of the social media team sits on an innovations committee. This individual reports changes in market, potential new innovations to help to improve our customer recruitment strategy";" our social media team contributes to the innovation process"; "the social media team supplies input to the innovation process for our company". 


\subsection{Brand image}

The company image is an important reason for a company to be present on social media. A good presence would keep current customers happy and attract new ones. It would also improve the brand value of the company. To present a good image, firms for example use social media to "show what it is like to work there and show happy employees having fun at work and creating a warm and friendly environment". Some examples of what participants said included: "it is important that we are present and responsive so that people continue to spread our name in a positive light"; "to get our name and what we do in front of a much broader market in real time";" company always need to display a positive image"; "we share what is happening in to improve the image".

\subsection{Capability}

In their responses, participants explained who and how they collect social media data, in order to benefit from this data. Based on that, this theme emerged: IT capability. Participants explained that the IT team was responsible to collect and analyse the data: "the IT department collect trends"; "the data would first be analysed in the IT department"; "a process (data collection) done by our IT department". Participants also named different software packages they use to collect and analyse the data:" we collect it within our IT department both on onsite servers as well as cloud based servers"; "we use the existing social media analytics tools in addition to special products such as Share Rocket"; "we use built in programs with each social media account, as well as hoot suite"; "keyhole because it gives you access to an intuitive and shareable dashboard, it tracks hashtag, keyword and campaign metrics in real-time."

\section{DISCUSSIONS AND CONCLUSIONS}

A total of 11 themes emerged from the data. We classified these themes into three main categories: social media initiatives, social media impact, and social media facilitators. The social media facilitators are what could be potentially the link between initiatives and the impact. We used themes from all three categories to develop our conceptual model.

The first category is social media initiatives, which included seven themes. Out of these social initiatives, three were consistent with previous studies (Lam et al., 2016; Kiron et al., 2013; Kane et al., 2014): customer service, product feedback and new ideas, and marketing and advertisement. We identified four new social media initiatives, representing new organizational purposes of firms' adoption of social media: needs identification, data collection and analysis, talent acquisition, and competitors tracking. The first new initiative identified, needs identification, was separated from customer service initiatives because it represents a proactive strategy while the customer service initiative represents a reactive strategy. Under a customer service initiative, firms are mainly reacting to customer inquiries and comments, answering their questions and solving any product related issues they are facing. However, under the needs identification initiative, firms are being proactive to search on social media for their customers' needs, which requires a process of collecting large amounts of data, analysing this data, and identifying common needs among their customers. The second new initiative identified was data collection and analysis. We noticed from our data that some companies just rely on reports available on the social media platforms they use, however many companies focus more on collecting the data from social media, analysing it, and uncovering valuable insights. Firms applying this initiative are making the most of their social media presence and will potentially have a competitive edge over firms who are not making use of this data. The third new initiative was talent acquisition, where firms are using social media to attract employees, especially the younger generations, as that is where they doing the job hunting nowadays. In order not to miss out on these talents, firms are using social media platforms for recruitment. The fourth new initiative was competitors tracking. Firms find social media an easy way to keep an eye on their competitors to track their latest products and offerings. Firms see social media as a low-cost opportunity for market research.

The second category of themes is social media impact. This category represents the effect of the firm's social media initiatives, on the firm itself. The themes under this category are: performance, innovation, and brand image. Our finding are consistent with previous research which studied the impact of social media on firms (Lam et al., 2016; Tajvidi and Karami, 2017; Wu, 2016; Kim et al., 2015). Social media initiatives affects firms' performance, who are using social media platforms, for example, for marketing purposes to attract more customers, which results in increase in sales, and as a result better performance results. It also has an impact on firms' innovativeness through the data collected and analysed, for example, which might reveal valuable insights. The last identified impact of social media initiatives was on brand image. For example having a strong presence on social media and sharing positive experiences raises the brand awareness and affects firms' brand image. 
The last category of themes doesn't represent neither an initiative nor an impact. We propose that it could potentially represent the link between the following social media initiatives and impacts: needs identification and data collection and analysis on one hand, and innovation and performance on the other hand. Hence, we considered this category as social media facilitators. We had one theme that belonged to this category, which is IT capability. To be able to extract data from social media and transfer this data into information and knowledge, firms need an advanced IT capability to download, store, and analyse the large amounts of data present on social media platforms for example.

Current literature has different studies addressing the impact of social media on different aspects of the firm such as innovativeness (Lam et al., 2016), performance (Tajvidi and Karami, 2017), and equity value (Luo et al., 2013).However, the studies that attempted to identify "which" specific social media initiative has an impact on "what" are very limited. Also, to the best of our knowledge, no previous study has attempted to use IT capability as the mediator of the relation between initiatives and impacts. Based on our findings, we developed a conceptual model built around IT capability as a mediator. We selected the initiatives that we believe is potentially linked and affected by firm's IT capability: needs identification and data collection and analysis. We also selected to potential areas of impact of these initiatives: innovation and performance. The reason why we discarded brand image from our model is because we think that area might better be affected by other initiatives such as marketing and advertisement. The model we propose is represented in figure 1.

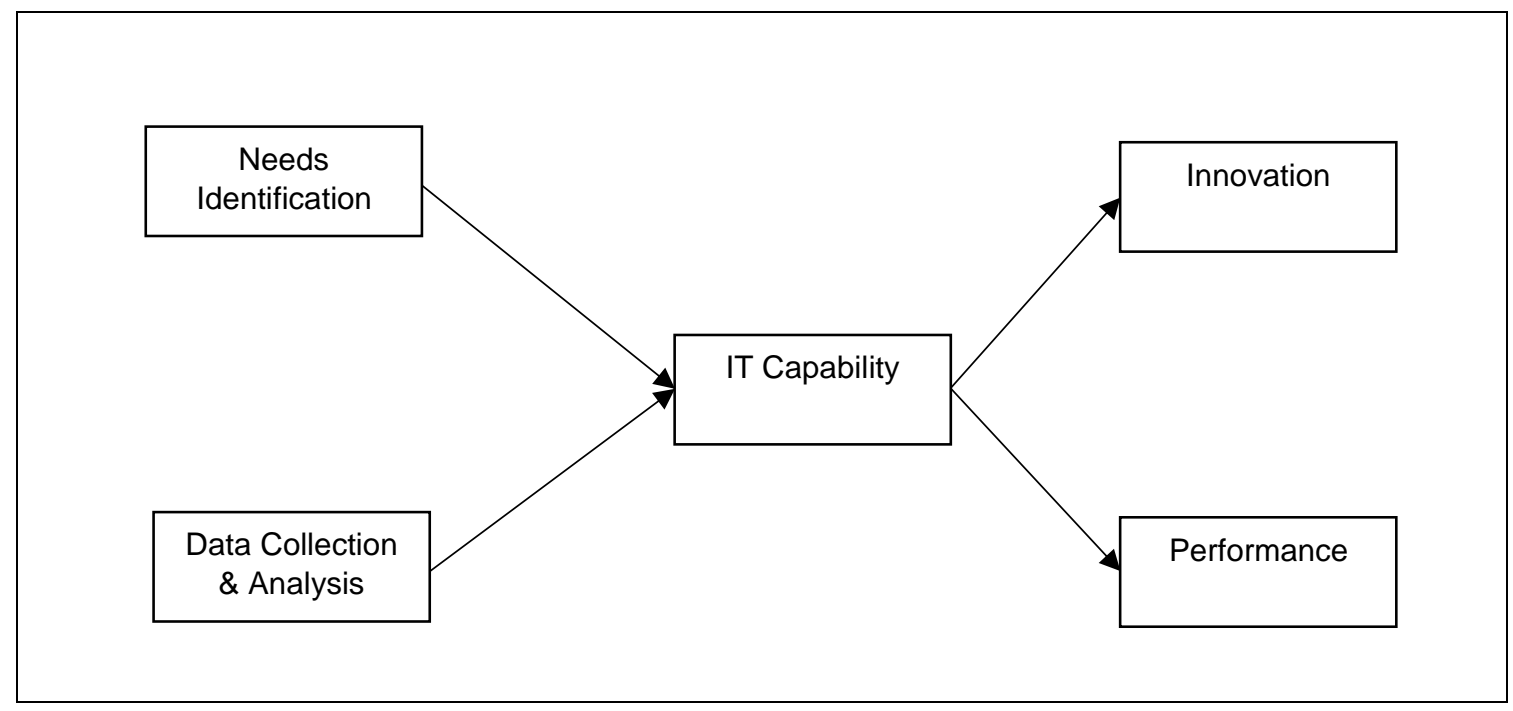

Note: The figure presents the conceptual model

\subsection{Contributions}

This research makes three contributions to the literature on social media. First, we identified four new social media initiatives firms are applying in their social media strategy: needs identification, data collection and analysis, talent acquisition, and competitors tracking. Our research also identified three other initiatives which are consistent with previous research: customer service, product feedback and new ideas, and marketing and advertisement. Second, we identified IT capability as a social media facilitator, a potential mediator which could be the link between social media initiatives and social media impact. Third, we developed a conceptual model around IT capability, including two specific initiatives (needs identification and data collection and analysis) and two potential impacts of these initiatives mediated by IT capability (innovation and performance).

Our research also provide practical implications for managers. We present to practitioners seven social media initiatives that firms are applying, four of which are new initiatives not proposed in previous studies. So managers can consider to apply these initiatives in case they weren't, in order to acquire more value from social media. 


\subsection{Limitations and future work}

Our research has some limitations. First, we used an online survey to collect the data which limited our interaction with the participants. Second, the generalizability of our results is subject to certain limits as our participants all were from United States. As a result of our exploratory study, we developed of a conceptual model linking social media initiatives to social media impact through IT capability. For future studies, we encourage researchers to increase sample size and consider more locations, as well as test our model with empirical data.

\section{References}

Aichner, T., and Jacob, F. 2015. "Measuring the Degree of Corporate Social Media Use," International Journal of Market Research (57:2), pp. 257-275.

Bang, N., Yu, X., Melewar, T. C., and Chen, J. 2015. "Brand Innovation and Social Media: Knowledge Acquisition from Social Media, Market Orientation, and the Moderating Role of Social Media Strategic Capability," Industrial Marketing Management (51), pp. 11-25.

Bashir, M., and Aldaihani, A. 2017. "Public Relations in an Online Environment: Discourse Description of Social Media in Kuwaiti Organizations," Public Relations Review (43:4), pp. 777-787.

Bashir, N., Papamichail, K. N., and Malik, K. 2017. "Use of Social Media Applications for Supporting New Product Development Processes in Multinational Corporations," Technological Forecasting and Social Change (120), pp. 176-183.

Bennett, S., 2013. Incredible statistics, facts and figures from the social media revolution. Available at <http://www.mediabistro.com/alltwitter/socialrevolutionb37610>.

Boateng, H., and Okoe, A. F. 2015. "Consumers' Attitude Towards Social Media Advertising and Their Behavioural Response the Moderating Role of Corporate Reputation," Journal of Research in Interactive Marketing (9:4), pp. 299-312.

Boyatzis, R.E. 1998: Transforming qualitative information: thematic analysis and code development. Sage.

Braun, V. \& Clarke, V. (2008) Using thematic analysis in psychology, Qualitative Research in Psychology, 3:2, 77-101

Bryman, A. (2012). Social Research Methods. Oxford: Oxford University Press Publications, Fourth Edition.

Carr, J., Decreton, L., Qin, W., Rojas, B., Rossochacki, T., and Yang, Y. W. 2015. "Social Media in Product Development," Food Quality and Preference (40), pp. 354-364.

Chang, H.-L., Chou, Y.-C., Wu, D.-Y., and Wu, S.-C. 2018. "Will Firm's Marketing Efforts on Owned Social Media Payoff? A Quasi-Experimental Analysis of Tourism Products," Decision Support Systems (107), pp. 13-25.

Charmaz, K. (2006). Constructing grounded theory: A practical guide through qualitative research. London, UK: Sage.

Charmaz, K. (2014). Constructing grounded theory, 2nd ed. London:Sage.

Chen, Y., Fay, S., and Wang, Q. 2011. "The Role of Marketing in Social Media: How Online Consumer Reviews Evolve," Journal of Interactive Marketing (25:2), pp. 85-94.

Correa, T., Hinsley, A. W., and de Zuniga, H. G. 2010. "Who Interacts on the Web?: The Intersection of Users' Personality and Social Media Use," Computers in Human Behavior (26:2), pp. 247-253.

Cornwell, T. (2013). Now, Big Data May Be the Next Big Thing. National Mortgage News, 37(28), pp. 6-n/a.

Creswell, J. (2012). Qualitative inquiry and research design: Choosing among five traditions. Thousand Oaks, CA: Sage.

Creswell, J. (2014). Research Design Qualitative, Quantitative, and Mixed Methods Approaches. London: Sage Publications, Fourth Edition.

Cruz, D \& Fill, C. (2008) Marketing Intelligence and planning. Journal of Marketing Practice and Applied Marketing Science, 26(7): 743-758.

Curtis, G. (2012). BIG Data Unlocks Business Value. Article by Greengard, S. Baseline, (114), pp. 20-23.

Lohr, S. (2012). 'The Age of Big Data'. The New York Times, 11/02/2012, p. n/a.

Falt, E., Sarkadi, A., and Fabian, H. 2017. "Exploring Nurses', Preschool Teachers' and Parents' Perspectives on Information Sharing Using Sdq in a Swedish Setting - a Qualitative Study Using Grounded Theory," Plos One $(12: 1)$.

Flick, U. (2014). An Introduction to Qualitative Research. London: Sage Publications, Fifth Edition.

Geyer, S., and Krumay, B. 2015. "Development of a Social Media Maturity Model - a Grounded Theory Approach," 48th Annual Hawaii International Conference on System Sciences (HICSS), Kauai, HI, pp. 1859-1868.

Glaser, B. G., \& Strauss, A. (1967). The discovery of grounded theory: Strategies for qualitative research. Chicago, IL: Aldine.

Glaser, B. (2003). The grounded theory perspective II: Description's remodelling of grounded theory methodology. Mill Valley, CA: Sociology Press.

Hajli, M. (2013). A research framework for social commerce adoption. Information Management \& Computer Security, 21(3), 144-154. 
Kamboj, S., Kumar, V., and Rahman, Z. 2017. "Social Media Usage and Firm Performance: The Mediating Role of Social Capital," Social Network Analysis and Mining (7:1).

Kane, G.C., Palmer, D., Phillips, A.N., Kiron, D., Buckley, N., 2014. Moving Beyond Marketing: Generating Social Business Value Across the Enterprise. MIT Sloan Management Review, Cambridge, MA.

Kangas, P., Toivonen, S., \& Bäck, A. (2007). "Ads by Google" and other social media business models. VTT.

Kaplan, A. M., and Haenlein, M. 2010. "Users of the World, Unite! The Challenges and Opportunities of Social Media," Business Horizons (53:1), pp. 59-68.

Kim, A. J., and Johnson, K. K. P. 2016. "Power of Consumers Using Social Media: Examining the Influences of BrandRelated User-Generated Content on Facebook," Computers in Human Behavior (58), pp. 98-108.

Kim, S., Koh, Y., Cha, J., and Lee, S. 2015. "Effects of Social Media on Firm Value for Us Restaurant Companies," International Journal of Hospitality Management (49), pp. 40-46.

Kiron, D., Palmer, D., Phillips, A.N., Kruschwitz, N., 2012. Social Business: What Are Companies Really Doing? MIT Sloan Management Review, Cambridge, MA.

Kiron, D., Palmer, D., Phillips, A.N., Berkman, R., 2013. Social Business: Shifting Out of First Gear. MIT Sloan Management Review, Cambridge, MA.

Lam, H. K. S., Yeung, A. C. L., and Cheng, T. C. E. 2016. "The Impact of Firms' Social Media Initiatives on Operational Efficiency and Innovativeness," Journal of Operations Management (47-48), pp. 28-43.

Luo, X., Zhang, J., and Duan, W. 2013. "Social Media and Firm Equity Value," Information Systems Research (24:1), pp. 146-163.

Michaelidou, N., Siamagka, N. T., and Christodoulides, G. 2011. "Usage, Barriers and Measurement of Social Media Marketing: An Exploratory Investigation of Small and Medium B2b Brands," Industrial Marketing Management (40:7), pp. 1153-1159.

Mount, M., and Martinez, M. G. 2014. "Rejuvenating a Brand through Social Media," Mit Sloan Management Review (55:4), pp. 14-16.

Parise, S., Iyer, B. and Vesset, D. (2012). Four Strategies to Capture and Create Valuefrom Big Data. Ivey Business Journal Online, , pp. 1.

Rodriguez, N. S. 2016. "Communicating Global Inequalities: How Lgbti Asylum-Specific Ngos Use Social Media as Public Relations," Public Relations Review (42:2), pp. 322-332.

Schaupp, L. C., \& Belanger, F. (2013). The value of social media for small businesses. Journal of Information Systems, 28(1), 187-207.

Schroeder, R., and Meyer, E.T. (2012) Big Data: What's New? Paper presented at Internet, Politics, Policy 2012 : Big Data, Big Challenges?, University of Oxford, UK.

Seo, E.-J., and Park, J.-W. 2018. "A Study on the Effects of Social Media Marketing Activities on Brand Equity and Customer Response in the Airline Industry," Journal of Air Transport Management (66), pp. 36-41.

Strauss, A., \& Corbin, J. (1990). Basics of qualitative research - Grounded theory procedures and techniques. Thousand Oakes, CA: Sage.

Strauss, A., and Corbin, J., "Grounded Theory Methodology", Handbook of qualitative research, 1994, pp. $273-285$.

Strübing, J. (2007). Research as pragmatic problem-solving: The pragmatist roots of empirically-grounded theorizing. In A. Bryant \& K. Charmaz (Eds.), The sage handbook of grounded theory (pp. 580-602). Thousand Oaks, CA: Sage.

Swani, K., Brown, B. P., and Milne, G. R. 2014. "Should Tweets Differ for B2b and B2c? An Analysis of Fortune 500 Companies' Twitter Communications," Industrial Marketing Management (43:5), pp. 873-881.

Tajvidi, R., and Karami, A. 2017. "The Effect of Social Media on Firm Performance," Computers in Human Behavior).

Trainor, K. J., Andzulis, J., Rapp, A., and Agnihotri, R. 2014. "Social Media Technology Usage and Customer Relationship Performance: A Capabilities-Based Examination of Social Crm," Journal of Business Research (67:6), pp. 12011208.

Urquhart, C. (2007). The evolving nature of grounded theory method: The case of the information systems discipline. In A. Bryant \& K. Charmaz (Eds.), The sage handbook of grounded theory (pp. 339-359). Thousand Oaks, CA: Sage.

Vesset, D. (2013). Big Data: Interview with the Experts. Interview by Judith Lamont. KM World, Vol 22(1), pp. 67,20 .

Viswanathan, K. (2012). BIG Data Unlocks Business Value. Article by Greengard, S. Baseline, (114), pp. 20-23.

Wang, W. Y. C., Pauleen, D. J., and Zhang, T. 2016. "How Social Media Applications Affect B2b Communication and Improve Business Performance in Smes," Industrial Marketing Management (54), pp. 4-14.

Ward, J. and Barker, A. (2013). Undefined By Data: A Survey of Big Data Definitions. arXiv:1309.5821, 2013. Featured in the MIT Technology Review.

Wu, C.-W. 2016. "The Performance Impact of Social Media in the Chain Store Industry," Journal of Business Research (69:11), pp. 5310-5316.

Yadav, M., and Rahman, Z. 2017. "Measuring Consumer Perception of Social Media Marketing Activities in E-Commerce Industry: Scale Development \& Validation," Telematics and Informatics (34:7), pp. 1294-1307.

Yu, Y., Duan, W., and Cao, Q. 2013. "The Impact of Social and Conventional Media on Firm Equity Value: A Sentiment

Analysis Approach," Decision Support Systems (55:4), pp. 919-926. 